\title{
Gruppo di famiglia in un interno
}

\section{Maria João Brilhante}

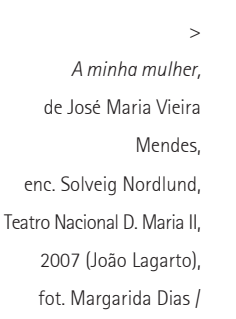

TNDMII.

10 Prémio foi instituido pelo Instituto Camões

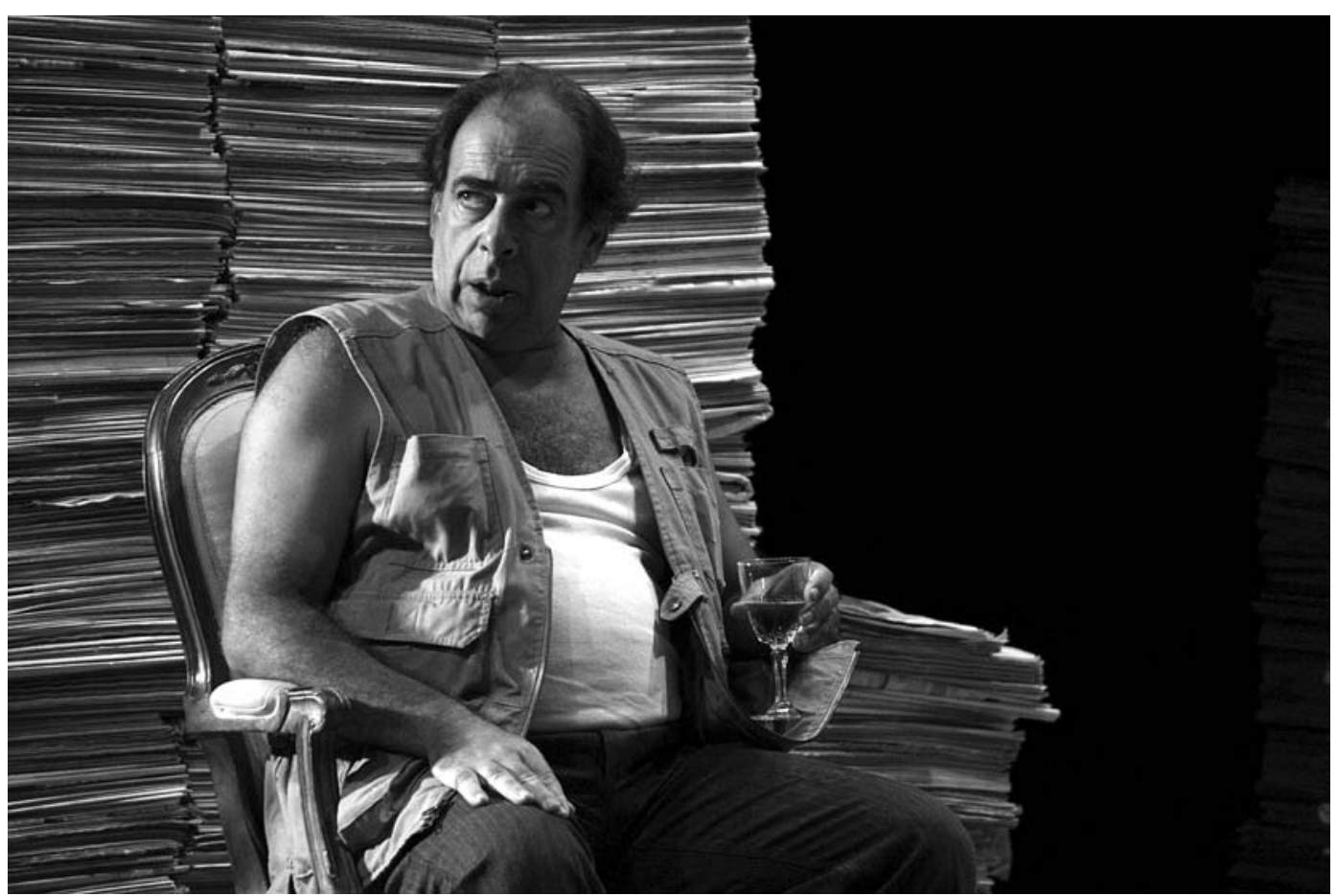

Titulo: A minha mulher (2007). Autor: José Maria Vieira Mendes. Encenação: Solveig Nordlund. Cenografia: Ulisses Cohn. Figurinos: Ana Paula Rocha. Música original: Pedro Marques. Desenho de luz: Carlos Marques. Interpretação: Dinarte Branco, Isabel Muñoz Cardoso, Joana Bárcia, João Lagarto e José Airosa. Produção: Teatro Nacional D. Maria II. Local e data de estreia: Teatro Nacional D. Maria II (Sala Estúdio), Lisboa, 19 de Setembro de 2007.

0 título é desde logo interpelador: A minha mulher. Um possessivo sinaliza sujeito e objecto, uma relação matrimonial invocada por uma expressão convencional que assinala grupo social e faixa etária. A mulher de que se fala interessa-nos, todavia, menos do que o sujeito que a ela se refere. Na verdade, desde a primeira cena será esse sujeito, o marido e pai de família, a impor-se através do seu discurso feito de lugares-comuns e da sua avassaladora energia.

0 texto de José Maria Vieira Mendes ganhou o prémio António José da Silva', já está publicado na colecção dos Livrinhos de Teatro dos Artistas Unidos e esteve na base deste espectáculo que Solveig Nordlund assinou. Consta que o ponto de partida para a sua escrita foi Brincar com o fogo de Strindberg, mas, como em tempos declarou o nosso jovem autor, escrever é sempre reescrever e neste caso a escrita operou uma interessante aproximação a um universo burguês, nosso contemporâneo. Não se trata apenas de uma transposição eficaz para um espaço-tempo sócio-cultural que nos é familiar, mas da verdadeira criação de um retrato de família portuguesa, que afoga no alcool a desilusão por nada ter estado ou estar agora à altura das suas expectativas, sabe-se lá quais elas sejam. Essa indecisão algo pinteriana, que é responsável pela acção deixada em aberto e pelo convite a que preenchamos os seus vazios com os nossos próprios fantasmas, não atinge, todavia, os graus de dúvida, de ameaça, de desesperança que encontramos em Strindberg, Bergman ou Pinter, para mencionar referências que o autor associa à sua experiência de leitor. As culturas do sul representam de outra forma a frustração.

Fala-se de autoritarismo, de fraqueza e cobardia, de dissimulação e do desejo inconfessável de "matar o pai". Tentativa sempre adiada de ajustar contas com a arrogância e a prepotência disfarçadas de abnegação e amor, palavra que ouvimos repetidas vezes no discurso moralizador desse pai. Curiosamente, este ambiente sempre em iminente estado de ruptura violenta, faz-nos sorrir por via de uma recorrente banalização da palavra, do, como se disse, dramatismo inconsequente do discurso e da acção: alguns insultos e ameaças não passam disso mesmo e a fragilidade das figuras não chega para que "levemos a sério" o aparecimento de uma arma de fogo em cena. Até ao incêndio que destruirá a casa de Verão da família, fica em 


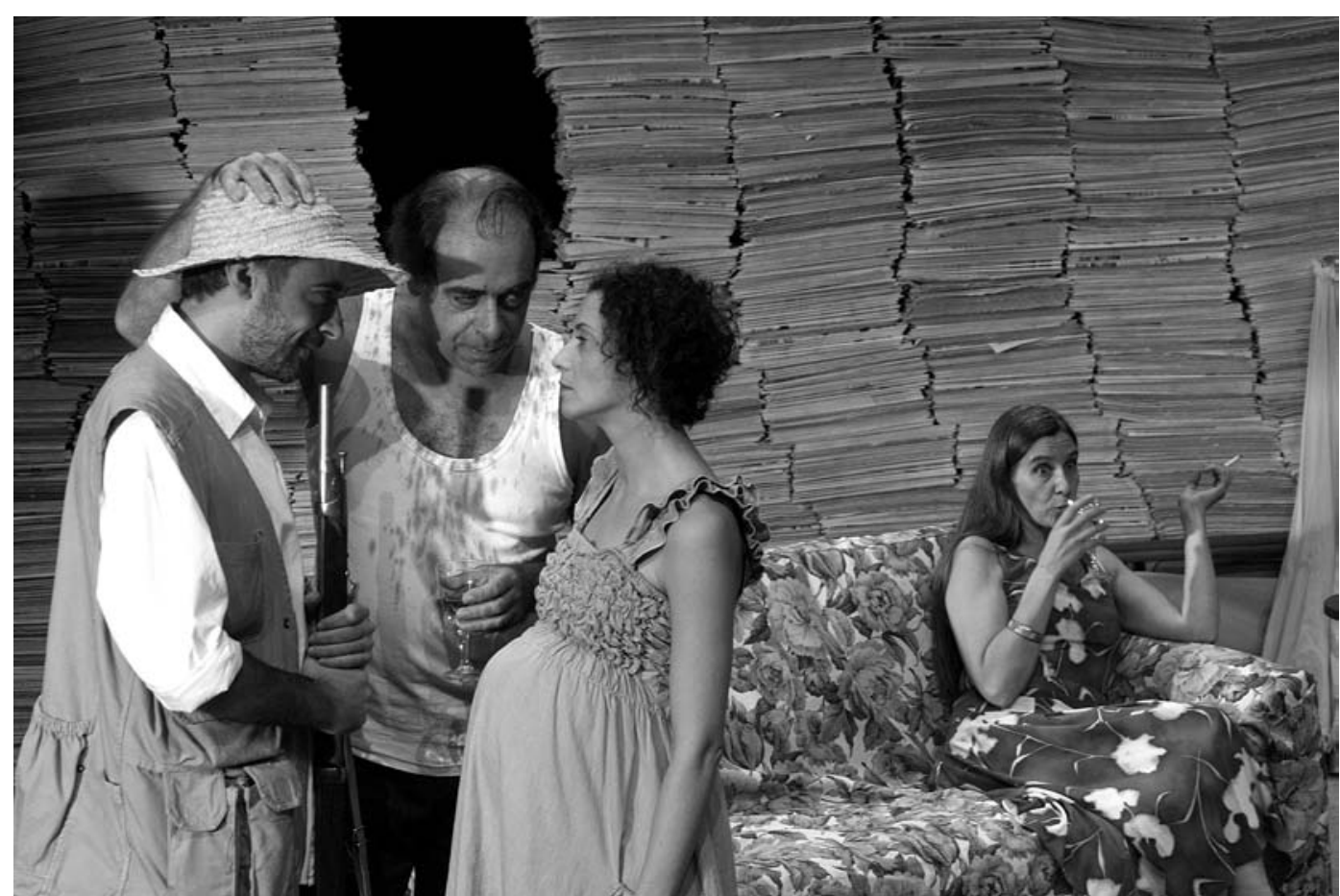

suspenso a concretização de um desfecho violento para a tensão representada. A impotência instalada encontra nesse gesto - o incêndio ateado pela nora - uma saída para as insuportáveis repetição e clausura. Brincar com o fogo deixa de ser metáfora, mas o drama não chega a entrar em cena (talvez por isso as últimas palavras sejam de chamamento: Laura... Laura.).

0 espectáculo começa, pois, por instalar um tom de divertimento que se manifesta na frase musical com que a acção arranca, ritmada e ligeira, evocativa do universo do cinema de animação (ou do de Jacques Tati...). Mas esses tom e ritmo também estão presentes na bem humorada troca de palavras que, de início, se sobrepõe à dureza de certas afirmações a revelarem lutas intestinas, ressentimentos, razões escondidas e histórias passadas guardadas nas memórias de cada um.

Se o texto se constrói a partir do modelo realista, cenicamente bem traduzido pela convencional sala e seus adereços (um cabide com chapéus de sol, cadeiras, sofás, duas mesas com garrafas e copos, jornais espalhados) e pelas roupas informais dos actores, depressa percebemos que à imagem não realista transmitida pela hipertrofia de jornais a fazerem de paredes da casa, também a fragmentação da acção e a repetição de cenas e discurso tornam a representação realista daquela família lassa e frágil, perturbando o eventual retrato de familia feliz, aquele mesmo que a mãe insiste em fazer ao brindar a mais um Verão passado em conjunto.

A mordacidade do diálogo surge envolvida em inesperadas piadas, jogos de palavras ou batalhas verbais e assim se fazem suceder quadros (conversation pieces ${ }^{2}$ ?) de interior onde as relações interhumanas calcam alguns lugares-comuns da "comédia de costumes": o filho que contesta o poder paterno, a mãe menorizada pela autoridade machista do marido, a nora que mostra dificuldade em aceitar o vazio e a inércia em que está mergulhada. Todas as personagens se observam a agir e deitam achas para o combate verbal. Todas menos uma, o amigo, que circunspecto e perturbador no seu laconismo irá ser usado (ao mesmo tempo que usa cada um dos outros) segundo os interesses dos membros da família: o desejo sexual da mãe, a cumplicidade do filho (que fantasia o assassinato do pai), a vontade de fuga da nora e 0 companheirismo viril do pai. Dinarte Branco desenha de forma muito convincente o discreto equilibrio entre apagamento e presença, entre inércia e acção, entre cumplicidade e distância, dando a ver uma figura que é tudo menos secundária e por onde se insinua um possivel "acontecimento", uma ruptura na circular e repetitiva acção.

Como cria Solveig Nordlund este clima, pois é sobretudo disso que se trata? Mantém aceso o despique a par de um subtil exercício de repetição de movimentos,
A minha mulher, de José Maria Vieira Mendes, enc. Solveig Nordlund, Teatro Nacional D. Maria II, 2007 (Dinarte Branco, João Lagarto, Joana Bárcia e Isabel Muñoz Cardoso), fot. Margarida Dias / TNDMII.

\footnotetext{
${ }^{2}$ Conversation piece é
} um género de pintura burguesa, representando ambientes informais de grupos conversando, muito em voga no século $X V I I I$, especialmente em Inglaterra com Hogarth. 


\section{A minha mulher, \\ de José Maria Vieira \\ Mendes, \\ enc. Solveig Nordlund, \\ Teatro Nacional D. Maria II, \\ 2007 (Dinarte Branco \\ e José Airosa), \\ fot. Margarida Dias /}

TNDMII.

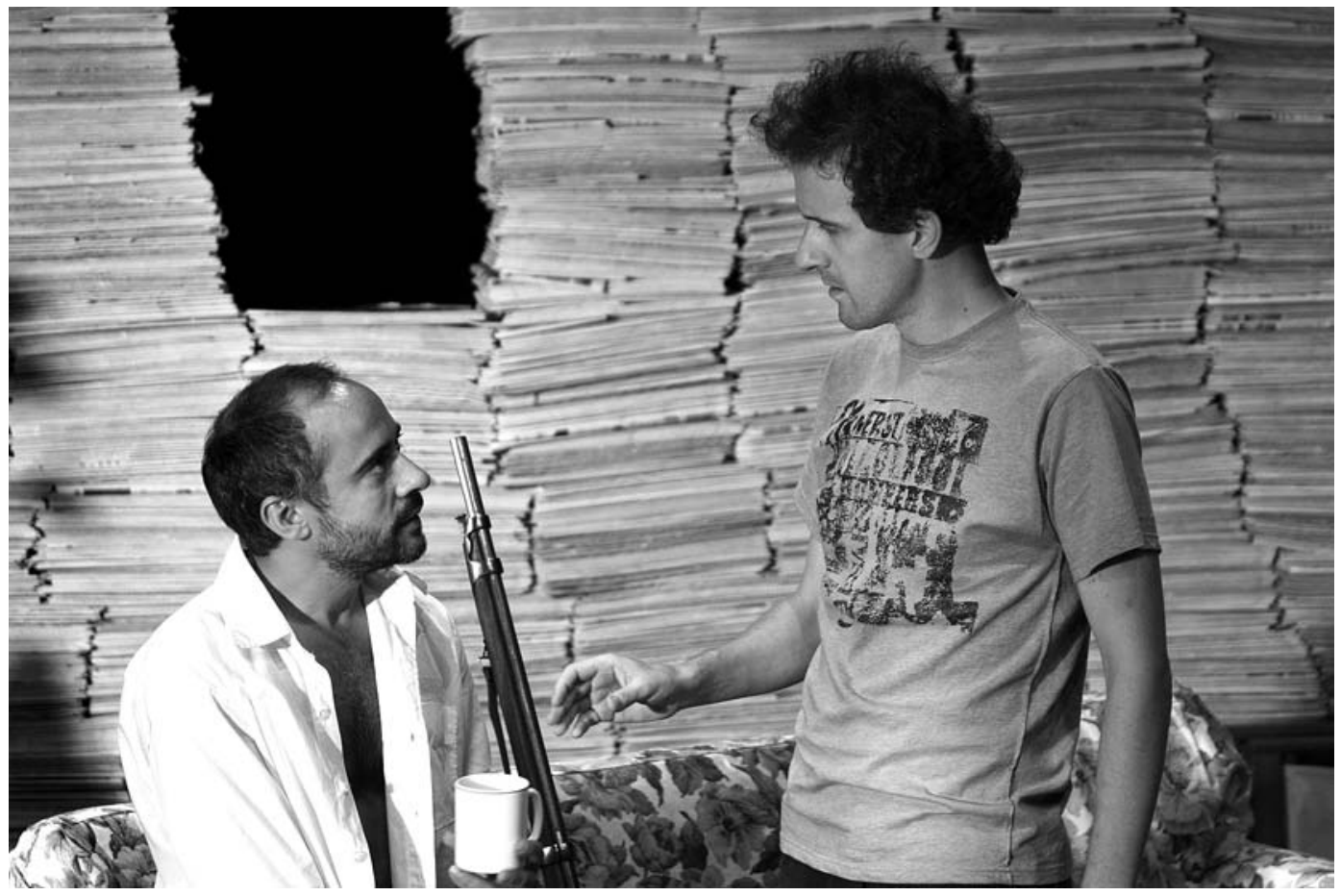

gestos, entoações, de forma a que, parecendo que nada avança ou acontece, tudo vá mudando e às frases repetidas como tiques, aos gestos tão banais e esterotipados na sua quase completa previsibilidade possamos atribuir diferentes sentidos pelo simples facto de os vermos mais uma vez, mas mais cansados, esgotada a sua frescura. Nada naquela casa é fresco (nem o ambiente onde se diz fazer um calor terrivel e cheirar mal), tudo aquilo já foi vivido num outro momento, mesmo (e sobretudo) a familiaridade grosseira do pai, a sua moral duvidosa, as suas recordações que não sabemos se são realmente suas ou de outrem, se são uma ficção ou a memória da sua vida reinventada. 0 enfado e o sentimento de inutilidade acometem todos com excepção desse voluntarioso pai, fazendo com que se arrastem pelos sofás, incapazes de encontrar uma razão válida para se mexerem, o que mais evidencia o frenesi, a agitação compulsiva do pai e o fascínio que isso parece provocar no amigo visitante. João Lagarto mobiliza as atenções dentro e fora de cena, sendo, aliás, curioso o jogo de atracção que desenvolve em certos momentos com o público, como que a buscar na sala uma cumplicidade legitimadora do seu esvaziado moralismo. Mas Joana Bárcia, na nora progressivamente mais agitada, José Airosa, no filho em quem crescem desconfianças, Isabel Muñoz Cardoso, na mulher entregue a resignada frustração são igualmente exemplares na construção de um jogo de tensões que crescem e esmorecem no interior de cada cena, fazendo-nos crer numa inevitável mas sempre adiada explosão.

0 espaço da cena está circundado, como se disse, por enormes pilhas de jornais, essas portas para o mundo do qual todos parecem desinteressados, não se preocupando sequer com a data do jornal que têm entre mãos. As saídas de casa vão rareando e apenas o pai mantém a rotina da ida ao mercado e dos treinos de pontaria com o amigo do filho. Nada muda em cena, talvez só o número de garrafas vazias, o jogo de ocupação das cadeiras e do sofá e os vestidos da mãe. A sua coquetterie contrasta com o desleixo das roupas das outras personagens e a desarrumação na sala. Beber, fumar e ouvir as lições de moral do pai, assistir ao espectáculo do colapso de uma família através da tranformação subtil que em cada um dos seus membros se vai operando é tudo o que acontece. No entanto, é na escuridão que marca o final das cenas e durante a qual a acção se prolonga que momentos reveladores têm lugar: a atracção sexual do pai pela nora, o desejo de matar o pai com a cumplicidade do amigo por parte do filho, por exemplo, ficam assim resguardados do nosso olhar, mas muito mais "iluminados" porque ouvimos a sua proferição.

0 tempo inicial do merecido descanso e harmonia familiar, depressa parece transformar-se num tempo opressivo, sem fim à vista. Só a barriga de Laura, a nora que se descobre estar grávida, sugere a passagem desse tempo circular onde não existem sinais de um antes e de um depois.

0 que o espectáculo oferece ao espectador - e isso talvez tenha sido mais perceptivel na última sessão, aquela a que assisti - é o prazer de acompanhar a criação de uma tão completa coesão entre os actores. Mobilizados para o propósito de nos manterem atraídos pela, como agora se diz, disfuncionalidade de uma familia, relançam entre si o jogo, sempre atentos a cada jogada, seguindo as reacções dos espectadores e respondendo aos desafios propostos pelo texto. Se a este prazer juntarmos o da descoberta de um texto contemporâneo onde se fala de nós, a felicidade é completa. 